University of Nebraska - Lincoln

DigitalCommons@University of Nebraska - Lincoln

Faculty Publications, Department of Child, Youth, and Family Studies

Child, Youth, and Family Studies, Department of

2021

Informal Caregivers' Well-Being at the Transition to Caregiving

Natalie A. Williams

Holly Hatton-Bowers

Kara Kohel

Shruti Pillai

Judith M. Burnfield

Follow this and additional works at: https://digitalcommons.unl.edu/famconfacpub

Part of the Developmental Psychology Commons, Family, Life Course, and Society Commons, Other Psychology Commons, and the Other Sociology Commons

This Article is brought to you for free and open access by the Child, Youth, and Family Studies, Department of at DigitalCommons@University of Nebraska - Lincoln. It has been accepted for inclusion in Faculty Publications, Department of Child, Youth, and Family Studies by an authorized administrator of DigitalCommons@University of Nebraska - Lincoln. 


\title{
Informal Caregivers' Well-Being at the Transition to Caregiving
}

\author{
Natalie A. Williams PhD, ${ }^{1}$ Holly Hatton-Bowers PhD, ${ }^{1}$ \\ Kara L. Kohel Ms, ${ }^{1}$ Shruti Pillai Bs, ${ }^{1}$ \\ and Judith M. Burnfield PhD, $\mathrm{PT}^{2}$ \\ 1 University of Nebraska-Lincoln, USA \\ 2 Madonna Rehabilitation Hospital, Lincoln, NE, USA \\ Corresponding author - Natalie A. Williams, Department of Child, Youth and Family \\ Studies, University of Nebraska-Lincoln, 231M Louise Pound Hall, P.O. Box 880236, \\ Lincoln, NE 68588-0236, USA. Email: nwilliams17@unl.edu
}

\begin{abstract}
The aim of this study was to describe the psychological and physical health needs of informal caregivers in a rehabilitation hospital and explore differences related to informal caregiver and care recipient characteristics. Readiness to engage in health promotion and perspectives on mindfulness meditation were assessed. Informal caregivers $(N=33)$ to patients receiving inpatient or outpatient treatment completed the Multidimensional Health Profile screening tools. Readiness to change was assessed using the readiness ruler approach. Almost half of participants (45.5\%) had a chronic illness and $18.2 \%$ reported that it interferes with daily functioning. Low Positive Health Habits were reported by $43 \%$ of participants, and Negative Health Habits were reported by $25 \%$. A subgroup (15\%-20\%) reported both physical and mental health concerns. A majority of participants indicated it was both

Published in Rehabilitation Counseling Bulletin 2021, vol. 64(4) 208-221.

DOI:10.1177/0034355220962186

Copyright (c) 2020 Hammill Institute on Disabilities; published by SAGE Publications. Used by permission.

Citation - Williams NA, Hatton-Bowers H, Kohel KL, Pillai S, Burnfield JM (2020). Informal caregivers' well-being at the transition to caregiving. Rehabilitation Counseling Bulletin, October 2020. DOI: 10.1177/0034355220962186
\end{abstract}


very important for them to improve their physical and mental health and felt very confident they could do so. Receptivity to mindfulness meditation was high, with $72.7 \%$ reporting an interest. Comprehensive screening and counseling interventions to address the physical and mental health of informal caregivers in physical rehabilitation hospital settings are needed, and information gained from screening could be addressed in interventions delivered by systems-oriented rehabilitation counselors. A mindfulness meditation intervention may be a useful strategy for promoting well-being in this population.

Keywords: family response to disability, health promotion, health and well-being, rehabilitation counseling process or strategies

Caregiving is increasingly recognized as a critical public health issue that affects quality of life for care providers as well as care recipients (Schulz \& Sherwood, 2008; Talley \& Crews, 2007). In the United States, millions of individuals spend a substantial amount of time serving as informal caregivers to friends or family members with disabilities or health conditions that impair their functional independence (Altman \& Blackwell, 2016; Edwards, 2020; Stevens et al., 2016). These informal caregivers provide an essential link between the health care system and home/community settings, often assuming complex medically related care responsibilities with limited training, preparation, or ongoing support to effectively manage caregiving demands. Although positive aspects of caregiving have been reported, such as having a positive outlook on life or appreciating life more (Choi et al., 2019; Yu et al., 2018), a growing literature highlights the challenging, stressful, and time-consuming nature of caregiving and the adverse effects of caregiving on the physical and mental health of the care provider (Adelman et al., 2014; Allen et al., 2017; Bouldin et al., 2018; Ochoa et al., 2019).

Understanding of caregiver well-being has increased exponentially in the last decade, yet important knowledge gaps persist. For example, the bulk of research on caregiver well-being has focused on well-being of informal family caregivers after they have been engaged in caregiving for an extended period of time (Adelman et al., 2014; Allen et al., 2017). Much less is known regarding caregiver physical and mental health at key transition points in the caregiving journey, including at the point at which the caregiving role is initiated. Documentation of the challenges facing caregivers when they initially assume caregiving 
responsibilities is critical to develop preventive interventions and reduce risk for adverse caregiver outcomes. Given evidence that caregiving impacts diverse factors that influence caregivers' quality of life (Geng et al., 2018; Liu et al., 2019; Or \& Kartal, 2019; Zavagli et al., 2016), it would be informative to comprehensively assess behaviors, attitudes, and symptoms that play a role in caregivers' health and psychosocial well-being. Moreover, much of what is known regarding the well-being of care providers is derived from studies predominately exploring the experiences of informal caregivers to children with developmental disabilities and informal caregivers to individuals with cancer (Frambes et al., 2017) or with Alzheimer's disease and other dementias (Tang et al., 2019). The extent to which existing findings regarding informal caregivers' needs and experiences generalize to other populations such as those caring for individuals impacted by strokes, brain injuries, or spinal cord injuries is limited. These informal caregiving experiences are also different in that they often occur without preparation for the caregiver role.

Emerging research is beginning to attend to not only the risk factors involved in informal caregiving but also to resilience-promoting factors. For example, in a recent study, dispositional mindfulness and perceived adaptive coping abilities of informal caregivers assessed during intensive care unit (ICU) hospitalization were associated with lower depressive symptoms at 3 and 6 months follow-up (Meyers et al., 2020). Mindfulness meditation interventions are of growing interest to support the well-being of informal caregivers (Dharmawardene et al., 2016). Mindfulness is often defined as an awareness that comes from paying attention to the present moment, without judgment and doing so with intention and purpose (Kabat-Zinn, 1994). When engaging in mindfulness, there is also a sense of openness and curiosity (Bishop et al., 2004). Often this attention is directed toward our feelings, thoughts, bodily sensations, and surrounding environment. Mindfulness meditation is one way to engage in this type of purposeful non-judging awareness. Simultaneous exploration of multiple components of wellbeing, including inter- and intrapersonal aspects of psychosocial functioning, and health habits/behaviors and health attitudes in addition to the presence of health problems, would provide a more comprehensive understanding of the intervention needs of informal caregivers. 
The medical rehabilitation setting provides an ideal, but under-researched, context for addressing identified gaps in the family caregiving literature because informal caregivers are frequently called upon to help facilitate recovery of function and independence following a serious injury or illness (Jolliffe et al., 2018; Nas et al., 2015; Winstein et al., 2016). To address this gap, the current study surveyed family caregivers of patients treated at a hospital specializing in the physical rehabilitation of children and adults with traumatic brain injuries, spinal cord injuries, severe stroke, and other neurologic, orthopedic, and complex medical conditions. Three research aims were explored. The first aim was to describe the physical and mental health of informal caregivers in a medical rehabilitation setting, including resilience-promoting factors such as coping and social support. The second aim was to examine whether physical and mental health needs vary according to the characteristics of the informal caregiver or care recipient. The third aim was to examine caregivers' perspectives on the importance of self-care and their experiences and interest in mindfulness meditation, a promising approach for reducing depression, anxiety, and stress in medical contexts (Dharmawardene et al., 2016).

\section{Method}

\section{Participants}

The socio-demographic characteristics of 33 informal caregivers who participated in the study are summarized in Table 1. Caregivers were primarily parents (36.4\%) or spouses (36.4\%) of patients. Their average age was 49.7 years $(S D=16.2)$ and most were married $(66.7 \%)$, identified themselves as White/Caucasian (78.8\%), and reported a college degree or some college (48.5\%) as their highest level of education attained. The majority of participants identified as female (75.8\%) and the remaining $\mathbf{2 4 . 2} \%$ identified as male. The most common diagnosis for caregivers' family members was brain injury/neurological condition/ stroke (63.6\%). The majority of participants $(84.8 \%)$ had a family member in inpatient care. Among the remainder, 9.1\% had a family member receiving intensive outpatient treatment and $6.1 \%$ had a family member in regular outpatient services. Length of treatment 
Table 1. Descriptive Characteristics of Participants.

\begin{tabular}{lr} 
Variable & $n(\%)$ \\
\hline Relationship to patient, $n$ (\%) & \\
Parent & $12(36.4)$ \\
Spouse or partner & $12(36.4)$ \\
Other & $9(27.3)$ \\
Age, $M$ (SD) & $49.7(16.2)$ \\
$21-30$ years & $6(18.2)$ \\
$31-40$ years & $4(12.1)$ \\
$41-50$ years & $6(18.2)$ \\
$51-60$ years & $7(21.2)$ \\
$61-70$ years & $8(24.2)$ \\
71 years or older & $2(6.0)$ \\
Marital status, $n$ (\%) & \\
Married or partnered & $22(66.7)$ \\
Not married or partnered a & $11(33.3)$ \\
Gender, $n$ (\%) & \\
Female & $25(75.8)$ \\
Male & $8(24.2)$ \\
Race/ethnicity, $n$ (\%) & \\
White/Caucasian & $26(78.8)$ \\
Hispanic & $7(21.2)$ \\
Asian/Pacific Islander & $2(6.1)$ \\
Black/African American & $1(3.0)$ \\
Native American & $1(3.0)$ \\
Biracial or multiracial & $1(3.0)$ \\
Educational attainment, $n$ (\%) & \\
High school or less & $11(33.3)$ \\
Some college or college degree & $16(48.5)$ \\
Some graduate school or graduate degree & $6(18.2)$ \\
Family member's diagnosis, $n$ (\%) & \\
Brain injury, neurological condition, or stroke & \\
Spinal cord injury or orthopedic condition & $21(63.6)$ \\
Other medical condition & $9(27.3)$ \\
\hline & $3(9.1)$ \\
\hline &
\end{tabular}

a. Includes single/never married, separated/divorced, and widowed.

$+p<.10$

time at this hospital for participants' family members was as follows: $39.4 \%$ less than 1 month, $36.4 \% 1$ to 2 months, $15.2 \% 3$ to 4 months, and $9.1 \%$ more than 6 months.

\section{Procedure}

Informal caregivers to adults or pediatric patients who were receiving care at a Midwest medical rehabilitation hospital following a severe injury or illness were recruited on-site at the hospital between 
October 2017 and May 2018. The facility specializes in rehabilitating patients who have experienced stroke, spinal cord injury, brain injury, complex medical issues, and a variety of other conditions or traumatic events, and provides a complete continuum of post-acute services, including inpatient rehabilitation, a long-term acute care hospital, subacute rehabilitation services, outpatient services, an extended care program, and day rehabilitation services. A table was set up in public spaces (e.g., waiting rooms, cafeteria), and rotated locations to ensure that the study was visible to caregivers of patients from various hospital treatment programs. The table was staffed by undergraduate research assistants who advertised the study using a recruitment poster affixed to the table.

Individuals who approached the recruitment table were provided with study information and screened for eligibility (i.e., over age 19 and an informal caregiver to an individual with a chronic health problem or disability who is being treated at the hospital in an inpatient or outpatient program). After obtaining written informed consent, participants were provided a survey packet. In appreciation of completing the study questionnaires, each participant was given a reusable water bottle. The study was approved by the Institutional Review Boards overseeing the research.

\section{Measures}

The Multidimensional Health Profile, including both the Health Functioning (MHP-H) and Psychosocial Functioning (MHP-P) components, was used to quantify participants' physical and mental health care utilization, health beliefs and attitudes, health habits, life stress, coping skills, social resources, and mental health functioning (Karoly et al., 2005; Ruehlman et al., 1999). The MHP-H consists of 69 items grouped in five areas that measure response to illness, health habits, health history, health care utilization, and health beliefs and attitudes. The MHP-P is made up of 58 items grouped into four main areas that measure life stress, coping, social resources, and mental health (including life satisfaction and psychological distress).

Raw scores from the MHP-P and MHP-H item responses were converted to standardized $T$-scores and interpreted following the established conventions in the assessment manual. For most scales and 
subscales, a $T$-score of 60 is 1 standard deviation above the normal average (50) and is considered moderate in severity, while a $T$-score of 70 represents high severity. For all scales and subscales, the higher the $T$-score, the more severe problems the respondent endorses. The MHP-P and MHP-H scales demonstrated good test-retest reliability as well as convergent and discriminant validity (Karoly et al., 2005; Ruehlman et al., 1999). Cronbach's alpha was estimated for MHP-P and the MHP-H scales and subscales in the current study sample. Most scales were found to have acceptable internal consistency $(\alpha=.72-$ .91). On the MHP-P, three subscales had Cronbach's alphas below .70, including Depressed Affect ( $\alpha=.58$, three-item scale), Anxious Affect ( $\alpha=.68$, three-item scale), and Cognitive Disturbance ( $\alpha=.40$, threeitem scale). On the MHP-H, four subscales had Cronbach's alphas below .70, including Self-Help ( $\alpha=.65$, three-item scale), Health Values ( $\alpha=.65$, four-item scale), Trust in the Health Care System ( $\alpha=$ .49 , three-item scale), and Hypochondriasis ( $\alpha=.58$, four-item scale).

Participants' readiness to make changes in their physical and mental health was assessed using the readiness ruler approach (Miller \& Rollnick, 2002). Participants rated how important it was for them to improve their physical health using a scale ranging from o (not at all important) to 10 (very important). Next, participants rated how confident they were that they could improve their physical health, if they decided to, using the same o to 10 rating scale. The same procedure was then used to assess participants' beliefs regarding importance and confidence of improving their mental health/emotional well-being. For descriptive purposes, participants' responses were collapsed as follows: 0 to $3=$ not at all important/not at all confident, 4 to $7=$ somewhat important/somewhat confident, and 8 to $10=$ very important/very confident.

Participants indicated their familiarity with mindfulness meditation using the following two questions: (a) Have you ever heard of mindfulness meditation? (yes/no), and (b) Have you ever practiced mindfulness meditation? (yes/no). The following item assessed participants' interest in learning more about mindfulness meditation: Mindfulness meditation has been shown to improve overall health and emotional well-being. Is this something you would be interested in learning more about? (yes/no). 


\section{Results}

\section{Psychosocial Functioning}

T-scores and follow-up recommendations based on MHP-P scores and cutoffs specified in the manual are presented in Table 2. "Suggested" follow-up evaluations were identified by the screening tool based on responses in the four domains (Life Stress, Coping, Social Resources, and Mental Health), with the Anxious Affect subscale and Social Support scale yielding the greatest percentages of suggested follow-up evaluations (33.3\% and 30.3\%, respectively). In addition, the screening tool pointed to the "Strongly Recommended" need for follow-up evaluations for a high percentage of participants in response to Somatic Complaints (27.3\%) and Guilt (12.1\%) within the Psychological Distress scale (21.2\%), Tangible Support issues (15.2\%) within the Social Support scale, and Perceived Stress (12.1\%).

Table 2. Caregivers' Scores on the MHP Psychosocial Functioning Screener.

\begin{tabular}{|c|c|c|c|c|c|}
\hline \multirow{2}{*}{$\begin{array}{l}\text { Domain } \\
\text { Scale } \\
\quad \text { Subscale }\end{array}$} & \multicolumn{3}{|c|}{ T-score } & \multicolumn{2}{|c|}{ Follow-up evaluation (\%) } \\
\hline & M & $S D$ & Range & Suggested $a$ & $\begin{array}{l}\text { Strongly } \\
\text { recommended }\end{array}$ \\
\hline \multicolumn{6}{|l|}{ Life stress } \\
\hline Number of Stressful Events & 52.1 & 10.1 & $37-72$ & 21.1 & 6.1 \\
\hline Perceived Stress & 50.9 & 12.0 & $37-80$ & 9.1 & 12.1 \\
\hline Coping & 49.1 & 8.2 & $33-67$ & 12.1 & 0.0 \\
\hline \multicolumn{6}{|l|}{ Social resources } \\
\hline Negative Social Exchange & 51.0 & 11.7 & $37-85$ & 3.0 & 9.1 \\
\hline Social Support & 54.2 & 11.7 & $38-84$ & 30.3 & 9.1 \\
\hline Emotional Support & 51.8 & 9.3 & $41-76$ & 15.2 & 3.0 \\
\hline Informational Support & 52.8 & 9.4 & $37-75$ & 18.2 & 3.0 \\
\hline Tangible Support & 54.4 & 12.3 & $41-83$ & 21.2 & 15.2 \\
\hline \multicolumn{6}{|l|}{ Mental health } \\
\hline Life Satisfaction & 53.3 & 9.4 & $35-70$ & 18.2 & 9.1 \\
\hline Psychological Distress & 54.7 & 12.3 & $35-76$ & 9.1 & 21.2 \\
\hline Depressed Affect & 48.2 & 13.3 & $25-74$ & 12.1 & 6.1 \\
\hline Guilt & 53.8 & 11.3 & $37-72$ & 24.2 & 12.1 \\
\hline Motor Retardation & 55.3 & 10.3 & $36-74$ & 21.2 & 9.1 \\
\hline Anxious Affect & 54.5 & 9.2 & $38-72$ & 33.3 & 3.0 \\
\hline Somatic Complaints & 55.2 & 12.3 & $42-78$ & 3.0 & 27.3 \\
\hline Cognitive Disturbance & 52.6 & 10.0 & $36-72$ & 21.2 & 6.1 \\
\hline
\end{tabular}

MHP = Multidimensional Health Profile.

a. Includes individuals with $T$-scores from 60 to 69 . blncludes individuals with $T$-scores $\geq 70$. 
Physical Health Status, Health Care Utilization, and Health Habits of Informal Caregivers

Almost half of participants surveyed (45.5\%) indicated that they have a chronic illness lasting 6 months or longer, which is similar to the prevalence of individuals reporting a chronic health condition in the United States (Buttorff et al., 2017). Nearly a fifth (18.2\%) of participants with a chronic illness reported that it interfered significantly with their daily functioning. Almost a quarter of participants (24.2\%) reported visiting their physician 3 to 5 times in the past year (excluding visits for pregnancy), and $\mathbf{1 5 . 2 \%}$ reported six or more office visits. Six percent of participants reported two to five separate overnight hospital admissions in the past 12 months and 9.1\% of participants reported receiving treatment at emergency room 3 to 5 times over the same time period. Participants endorsed low Positive Health Habits more than Negative Health Habits. Regarding the former, 27.3\% of participants were suggested for follow-up and $15.2 \%$ were strongly recommended for follow-up. Comparatively, for Negative Health Habits, $12.1 \%$ of participants were suggested for follow-up and another $12.1 \%$ were strongly recommended for follow-up.

Response to Illness, Health Beliefs, and Health Attitudes

The majority of respondents (89.9\%) described their typical illness as mild or moderate versus serious (3.0\%) or very serious $(6.1 \%)$. Examination of participants' help-seeking behaviors in response to their typical illness revealed that follow-up was suggested for a third of individuals across all four help-seeking scales, including Self-Help (33.3\%), Professional Help (36.4\%), Help From Friends (30.3\%), and Spiritual Help (30.3\%); however, few individuals scored in the strongly recommended for follow-up range (see Table 3). A similar pattern was observed for the scales comprising the health beliefs and attitudes domain. Specifically, although a fifth to over a third of participants surveyed were identified as suggested for follow-up across all scales (with the exception of Hypochondriasis), fewer individuals were strongly recommended for follow-up. 
Table 3. Caregivers' Scores on the MHP Health Functioning Screener.

\begin{tabular}{|c|c|c|c|c|c|}
\hline \multirow{2}{*}{$\begin{array}{c}\text { Domain } \\
\text { Scale }\end{array}$} & \multicolumn{3}{|c|}{$T$-score } & \multicolumn{2}{|c|}{ Follow-up evaluation (\%) } \\
\hline & M & $S D$ & Range & Suggested ${ }^{a}$ & $\begin{array}{c}\text { Strongly } \\
\text { recommended }\end{array}$ \\
\hline \multicolumn{6}{|l|}{ Response to illness ${ }^{c}$} \\
\hline Self-Help & 48.8 & 9.6 & $36-73$ & 33.3 & 3.0 \\
\hline Professional Help & 51.7 & 9.7 & $33-69$ & 36.4 & 0.0 \\
\hline Help From Friends & 53.8 & 9.7 & $39-77$ & 30.3 & 6.1 \\
\hline Spiritual Help & 54.9 & 9.7 & $34-75$ & 30.3 & 6.1 \\
\hline \multicolumn{6}{|l|}{ Health habits } \\
\hline Positive Health Habits & 55.7 & 10.9 & $32-73$ & 27.3 & 15.2 \\
\hline Negative Health Habits & 53.1 & 14.1 & $29-88$ & 12.1 & 12.1 \\
\hline \multicolumn{6}{|l|}{ Health beliefs and attitudes } \\
\hline Self-Efficacy & 51.6 & 10.2 & $36-76$ & 21.2 & 3.0 \\
\hline Health Vigilance & 53.6 & 11.1 & $30-71$ & 30.3 & 3.0 \\
\hline Health Values & 57.0 & 9.7 & $40-72$ & 39.4 & 3.0 \\
\hline Trust, Health Care Staff ${ }^{c}$ & 50.3 & 11.1 & $31-74$ & 36.4 & 3.0 \\
\hline Trust, Health Care System ${ }^{d}$ & 45.7 & 9.6 & $23-66$ & 27.3 & 3.0 \\
\hline Hypochondriasis & 51.0 & 10.1 & $36-82$ & 9.1 & 3.0 \\
\hline
\end{tabular}

MHP = Multidimensional Health Profile.

a. Includes individuals with $T$-scores from 60 to 69 , unless otherwise noted.

b. Includes individuals with $T$-scores $\geq 70$.

c. Follow-up suggested for individuals with $T$-scores less than or equal to 40 or 60-69.

d. Follow-up suggested for individuals with $T$-scores from 30 to 39 or 60 to 69 . Follow-up strongly recommended for individuals with $T$-scores less than or equal to 30 or $\geq 60$ or $\geq 70$.

\section{Associations Between Physical and Psychosocial Health}

To examine the relations between physical and psychosocial health concerns, all MHP scales and subscales were recoded to group participants as either $\mathrm{o}=$ no follow-up indicated or 1 = follow-up suggested or strongly recommended. MHP physical health scales and MHP psychosocial health scales/ subscales were then cross-tabulated to determine the percentage of participants for whom specific concerns were identified for an aspect of physical health as well as psychosocial health (see Table 4). A general pattern emerged with a substantial subgroup of participants (approximately 15\%- 20\%) identified for follow-up due to their Psychological Distress scores. This same subgroup was also identified for follow-up because of concerns related to low Help From Friends, low Positive Health Habits, and low Health Values. Additional overlapping areas of concern were observed for the 
Table 4. Percentage of Caregivers for Whom Follow-Up Was Suggested or Strongly Recommended for Physical and Psychosocial Subscales

\begin{tabular}{|c|c|c|c|c|c|c|c|c|c|c|c|}
\hline \multirow[b]{2}{*}{ MHP psychosocial scales } & \multicolumn{10}{|c|}{ MHP physical health scales } & \multirow[b]{2}{*}{$\begin{array}{l}\text { Trust in } \\
\text { System }\end{array}$} \\
\hline & $\begin{array}{l}\text { Self- } \\
\text { Help }\end{array}$ & $\begin{array}{c}\text { Profes } \\
\text {-sional } \\
\text { Help }\end{array}$ & $\begin{array}{l}\text { Help } \\
\text { From } \\
\text { Friends }\end{array}$ & $\begin{array}{c}\text { Spiritual } \\
\text { Help }\end{array}$ & $\begin{array}{c}\text { Positive } \\
\text { Health } \\
\text { Habits }\end{array}$ & $\begin{array}{c}\text { Negative } \\
\text { Health } \\
\text { Habits }\end{array}$ & $\begin{array}{c}\text { Self- } \\
\text { Efficacy }\end{array}$ & $\begin{array}{c}\text { Health } \\
\text { Vigilance }\end{array}$ & $\begin{array}{l}\text { Health } \\
\text { Values }\end{array}$ & $\begin{array}{l}\text { Trust in } \\
\text { Providers }\end{array}$ & \\
\hline Number of Stressful Events & 9.1 & 9.1 & 9.1 & 9.1 & 9.1 & 15.2 & 9.1 & 9.1 & 12.1 & 9.1 & 12.1 \\
\hline Perceived Stress & 9.4 & 6.3 & 6.3 & 6.3 & 6.3 & 9.4 & 6.3 & 6.3 & 9.4 & 9.4 & 12.5 \\
\hline Coping & 6.1 & 6.1 & 0.0 & 6.1 & 3.0 & 0.0 & 6.1 & 6.1 & 3.0 & 3.0 & 3.0 \\
\hline Negative Social Exchange & 3.0 & 6.1 & 0.0 & 3.0 & 6.1 & 0.0 & 3.0 & 0.0 & 12.1 & 3.0 & 6.1 \\
\hline Overall Social Support & 15.2 & 18.2 & 12.1 & 6.1 & 15.2 & 6.1 & 6.1 & 15.2 & 15.2 & 18.2 & 9.1 \\
\hline Emotional Support & 3.1 & 12.5 & 3.1 & 3.1 & 12.5 & 3.1 & 6.3 & 9.4 & 12.5 & 3.1 & 6.3 \\
\hline Informational Support & 6.1 & 15.2 & 6.1 & 3.0 & 9.1 & 3.0 & 3.0 & 9.1 & 9.1 & 6.1 & 6.1 \\
\hline Tangible Support & 15.2 & 12.1 & 12.1 & 9.1 & 12.1 & 6.1 & 6.1 & 9.1 & 15.2 & 15.2 & 3.0 \\
\hline Life Satisfaction & 9.1 & 0.0 & 12.1 & 0.0 & 15.2 & 9.1 & 9.1 & 9.1 & 15.2 & 6.1 & 3.0 \\
\hline Psychological Distress & 9.1 & 6.1 & 15.2 & 9.1 & 15.2 & 12.1 & 6.1 & 9.1 & 18.2 & 9.1 & 12.1 \\
\hline Depressed Affect & 6.1 & 3.0 & 9.1 & 3.0 & 12.1 & 3.0 & 3.0 & 6.1 & 9.1 & 9.1 & 6.1 \\
\hline Guilt & 12.1 & 6.1 & 18.2 & 9.1 & 18.2 & 12.1 & 9.1 & 12.1 & 21.2 & 12.1 & 12.1 \\
\hline Motor Retardation & 12.1 & 12.1 & 15.2 & 12.1 & 18.2 & 9.1 & 6.1 & 9.1 & 12.1 & 15.2 & 9.1 \\
\hline Anxious Affect & 12.1 & 3.0 & 15.2 & 6.1 & 18.2 & 12.1 & 9.1 & 9.1 & 21.2 & 12.1 & 9.1 \\
\hline Somatic Complaints & 9.1 & 6.1 & 12.1 & 6.1 & 18.2 & 9.1 & 9.1 & 9.1 & 15.2 & 9.1 & 9.1 \\
\hline Cognitive Disturbance & 9.1 & 9.1 & 15.2 & 9.1 & 9.1 & 12.1 & 6.1 & 6.1 & 15.2 & 12.1 & 12.1 \\
\hline
\end{tabular}

Numbers are percentages.

MHP = Multidimensional Health Profile.

Social Support domain with low Self-Help and low tendency to seek Professional Help in response to illness, low Health Vigilance, low Health Values, and Trust in Health Care Providers. Approximately 15\% of participants identified for follow-up due to the Number of Stressful Events they experienced in the past year were also identified for follow-up due to their scores on the Negative Health Habits scale. Participants identified for follow-up due to their feelings of Guilt were also identified for follow-up because of concerns related to low Help From Friends (18.2\%), low Positive Health Habits (18.2\%), and low Health Values (21.2\%).

\section{Caregiver/Patient Characteristics and Caregiver Well-Being}

Associations between caregiver/patient characteristics and followup classification on the MHP scales were estimated using analysis of variance (ANOVA) and chi-square analyses using SPSS version 25 . For these analyses, all MHP variables were coded as $1=$ no follow-up 
Table 5. Associations Between Caregiver and Patient Characteristics and Caregiver Well-Being.

\begin{tabular}{|c|c|c|c|c|c|c|}
\hline \multirow[b]{2}{*}{ MHP scale or subscale } & \multicolumn{5}{|c|}{ For $\chi^{2}$} & \multirow[b]{2}{*}{$\begin{array}{l}\text { Patient } \\
\text { diagnosis }\end{array}$} \\
\hline & Age & $\begin{array}{c}\text { Race/ } \\
\text { ethnicity }^{a}\end{array}$ & $\begin{array}{l}\text { Marital } \\
\text { status }\end{array}$ & $\begin{array}{l}\text { Educational } \\
\text { attainment }\end{array}$ & $\begin{array}{c}\text { Relationship } \\
\text { to patient }\end{array}$ & \\
\hline Number of Stressful Events & $3.43^{*}$ & 1.52 & 2.79 & 4.54 & 3.80 & 2.30 \\
\hline Perceived Stress & $2.58^{+}$ & 2.74 & 0.50 & 2.31 & 3.60 & 1.02 \\
\hline Coping & $2.89+$ & 1.23 & 0.14 & 1.58 & 2.75 & 2.60 \\
\hline Negative Social Exchange & 1.41 & 0.54 & 0.52 & 2.00 & 3.54 & 3.65 \\
\hline Overall Social Support & 0.12 & 4.48 & 4.35 & 1.77 & 4.94 & 2.90 \\
\hline Emotional Support & 0.29 & 3.69 & 2.37 & 2.40 & 4.82 & 1.47 \\
\hline Informational Support & 2.20 & 3.85 & 2.08 & 2.09 & 6.45 & 1.40 \\
\hline Tangible Support & 0.07 & $6.45^{*}$ & 2.74 & 4.59 & 2.67 & 3.14 \\
\hline Life Satisfaction & $5.00^{*}$ & $5.33^{\dagger}$ & 1.69 & 2.15 & 3.02 & 1.31 \\
\hline Psychological Distress & $2.98^{+}$ & 0.69 & 2.33 & 3.78 & 6.53 & 3.05 \\
\hline Depressed Affect & $3.94^{*}$ & 3.64 & 0.92 & 3.53 & $8.74{ }^{\dagger}$ & 6.20 \\
\hline Guilt & $3.53^{*}$ & 0.16 & 0.78 & 1.45 & 3.73 & 0.60 \\
\hline Motor Retardation & $3.12^{+}$ & 2.97 & $6.62^{*}$ & 3.54 & 4.43 & 7.02 \\
\hline Anxious Affect & 1.62 & 0.81 & 2.18 & 2.03 & 6.77 & 2.19 \\
\hline Somatic Complaints & 2.23 & 0.28 & 1.09 & 6.05 & 2.37 & 3.31 \\
\hline Cognitive Disturbance & 1.51 & 0.77 & 0.72 & 2.12 & 1.80 & 0.97 \\
\hline Self-Help & 2.07 & $4.77^{\dagger}$ & 3.35 & 2.88 & 2.86 & 6.05 \\
\hline Professional Help & 1.50 & $4.72^{*}$ & 2.36 & 1.38 & 1.67 & 0.35 \\
\hline Help From Friends & 2.17 & 1.06 & $5.06^{+}$ & 7.13 & 1.51 & 3.32 \\
\hline Spiritual Help & $2.66^{+}$ & 1.06 & 0.66 & 3.36 & 1.69 & 4.87 \\
\hline Positive Health Habits & $6.16^{\star *}$ & 3.15 & 0.13 & 2.84 & 5.47 & 1.07 \\
\hline Negative Health Habits & 0.27 & 1.23 & 1.32 & 6.28 & $12.83^{*}$ & 2.02 \\
\hline Self-Efficacy & $4.52^{*}$ & 0.59 & 2.09 & 2.62 & 7.67 & 3.41 \\
\hline Health Vigilance & $3.05^{+}$ & $4.93^{\dagger}$ & 4.36 & 3.01 & $11.73^{*}$ & 0.63 \\
\hline Health Values & 0.22 & 4.08 & 2.72 & 1.41 & 3.50 & 4.41 \\
\hline Trust, Health Care Staff & 0.37 & 0.59 & 0.53 & 2.54 & 4.11 & 0.73 \\
\hline Trust, Health Care System & 1.77 & 0.28 & 0.52 & 4.53 & 2.37 & 3.31 \\
\hline Hypochondriasis & 1.49 & 4.53 & 2.28 & 2.00 & 1.85 & 2.60 \\
\hline
\end{tabular}

MHP = Multidimensional Health Profile.

a. Race/ethnicity was coded as $0=$ White, $1=$ racial/ethnic minority (individuals identifying as Black/African American, Asian or Pacific Islander, Hispanic, Native American, and Biracial or Multiracial).

$+p<.10 ;{ }^{*} p<.05 ;{ }^{* *} p<.01$

indicated, 2 = follow-up suggested, 3 = follow-up strongly recommended. Results are summarized in Table 5. Caregiver age was significantly associated with Number of Stressful Events, $F(2,32)=3.43$, $p<.05$; Life Satisfaction, $F(2,32)=5.00, p<.05$; Depressed Affect, $F(2,32)=3.94, p<.05$; Guilt, $F(2,32)=3.53, p<.05$; Positive Health Habits, $F(2,32)=6.16, p<.01$; and Self-Efficacy, $F(2,32)=4.52, p<$ 
.05, with younger individuals generally scoring in the suggested follow-up range more frequently than older counterparts. Post hoc comparisons for Number of Stressful Events revealed that participants scoring in the suggested follow-up range were significantly younger than participants scoring in the no follow-up indicated range ( $M=$ 36.9 vs. 53.7 years). For Life Satisfaction, participants scoring in the follow-up strongly recommended range were significantly younger than participants scoring in the no follow-up indicated range ( $M=$ 29.0 vs. 54.2 years).

For Depressed Affect, participants scoring in the follow-up suggested and follow-up strongly recommended range were significantly younger than participants scoring in the no follow-up indicated range ( $M=34.0$ and 34.5 vs. 53.2 years). For Guilt, participants scoring in the follow-up strongly recommended range were significantly younger than participants scoring in the no follow-up indicated range ( $M=$ 39.0 vs. 55.0 years). For Positive Health Habits, participants scoring in the follow-up strongly recommended range were significantly younger than participants scoring in the no follow-up indicated range ( $M=30.6$ vs. 55.3 years). For Self-Efficacy, participants scoring in the follow-up suggested and follow-up strongly recommended range were younger than participants scoring in the no follow-up indicated range ( $M=38.4$ and 38.4 vs. 53.9 years).

Race/ethnicity was significantly associated with Tangible Social Support, $\chi^{2}(2, N=33)=6.45, p<.05$, and seeking Professional Help, $\chi^{2}(2, N=33)=4.72, p<.05$. Post hoc comparisons for Tangible Social Support revealed that significantly fewer individuals identifying as racial/ethnic minorities scored in the strongly recommended for follow-up range and more individuals identifying as White/Caucasian scored in the strongly recommended for follow-up range than would be expected by chance. For Professional Help seeking, significantly more individuals identifying as racial/ethnic minorities scored in the strongly recommended for follow-up range and fewer individuals identifying as White/Caucasian scored in the strongly recommended for follow-up range than would be expected by chance. Marital status was significantly associated with the Motor Retardation subscale of the Psychological Distress scale, $\chi^{2}(2, N=33)=6.62, p<.05$. Post hoc comparisons on the Motor Retardation subscale revealed that more unmarried/partnered individuals scored in the suggested follow-up 
range and fewer individuals identifying as White/Caucasian scored in the suggested follow-up range than would be expected by chance.

Relationship to patient was significantly associated with Negative Health Habits, $\chi^{2}(4, N=33)=12.83, p<.05$, and Health Vigilance, $\chi^{2}(4, N=33)=11.73, p<.05$. Post hoc comparisons revealed for Negative Health Habits-significantly fewer individuals identifying as spouses/partners and parents scored in the strongly recommended for follow-up range and more individuals identifying as "other" scored in the strongly recommended for follow-up range than would be expected by chance. For Health Vigilance, significantly more individuals identifying as spouses/partners and parents scored in the no follow-up indicated range and fewer individuals identifying as "other" scored in the no follow-up indicated range than would be expected by chance. No significant associations were observed for educational attainment and diagnosis of the caregivers' family member.

\section{Readiness to Change}

Participants' readiness to make changes with respect to their physical and mental health is summarized in Table 6. No participants endorsed making changes in physical or mental health as not at all important to them; likewise, no participants indicated that they were not at all confident in being able to make changes to their physical or

Table 6. Participants' Readiness to Make Changes to Improve Physical and Mental Health $(N=33)$.

\begin{tabular}{|c|c|c|c|}
\hline \multirow{2}{*}{$\begin{array}{l}\text { Rating of } \\
\text { Importance to } \\
\text { Make Changes }\end{array}$} & \multicolumn{3}{|c|}{ Confidence, $n$ (\%) } \\
\hline & Not at all & Somewhat & Very \\
\hline \multicolumn{4}{|c|}{ Importance, $n$ (\%) } \\
\hline \multicolumn{4}{|c|}{ Not at all } \\
\hline $\mathrm{PH}$ & $0(0.0)$ & $0(0.0)$ & $0(0.0)$ \\
\hline $\mathrm{MH}$ & $0(0.0)$ & $0(0.0)$ & $0(0.0)$ \\
\hline \multicolumn{4}{|l|}{ Somewhat } \\
\hline $\mathrm{PH}$ & $0(0.0)$ & $2(6.1)$ & $3(9.1)$ \\
\hline $\mathrm{MH}$ & $0(0.0)$ & $3(9.1)$ & $4(12.1)$ \\
\hline \multicolumn{4}{|l|}{ Very } \\
\hline $\mathrm{PH}$ & $0(0.0)$ & $4(12.1)$ & $24(72.7)$ \\
\hline $\mathrm{MH}$ & $0(0.0)$ & $1(3.0)$ & $25(75.8)$ \\
\hline
\end{tabular}

$\mathrm{PH}=$ physical health; $\mathrm{MH}=$ mental health . 
mental health. Regarding physical health, $72.7 \%$ of caregivers surveyed reported that it was both very important for them to improve their physical health and that they felt very confident they could do so, if they chose. Four participants (12.1\%) indicated that it was very important to them to improve their physical health, but only felt somewhat confident that they could make the desired changes. Regarding mental and emotional health, the majority of participants (78.8\%) indicated that improving their mental health was very important, and the majority of these individuals indicated that they felt very confident in that they could do so, if they chose.

Familiarity and Interest in Mindfulness Meditation

Over half (54.5\%) of participants reported that they had ever heard of mindfulness meditation, and 30.3\% indicated that they have ever practiced mindfulness meditation. Regarding receptivity to participating in mindfulness meditation, $72.7 \%$ reported that they were interested in learning more about this approach as a way to improve their wellbeing. Interest in mindfulness meditation did not differ as a function of caregiver age, $t(31)=1.79, p=.08$; gender, $\chi^{2}(1, N=$ $33)=0.56, p=.46$; educational attainment, $\chi^{2}(2, N=33)=3.52, p=$ .17; race/ethnicity, $\chi^{2}(1, N=33)=0.76, p=.39$; marital status, $\chi^{2}(1$, $N=33)=2.75, p=.10$; relationship to the hospitalized family member, $\chi^{2}(2, N=33)=3.73, p=.16$; or diagnosis of the caregivers' family member, $\chi^{2}(2, N=33)=0.35, p=.84$.

\section{Discussion}

A comprehensive understanding of the challenges facing family members when they initially assume caregiving responsibilities is critical to develop preventive interventions and reduce the risk for adverse caregiver and patient outcomes. The present study makes a unique contribution to the small literature focusing on the well-being of informal caregivers to individuals recovering from injury or illness in a medical rehabilitation hospital-a setting in which the role of informal caregiver for a family member with a chronic health condition is often initiated. The first aim of this study was to describe the psychosocial 
and physical health of informal caregivers. With respect to the former, we found that the social support needs of informal family caregivers are high at this time point, with a particular need in the area of tangible support (e.g., the provision of financial assistance, material goods, or services). Caregivers also reported elevated levels of psychological distress, including guilt, anxiety, and somatic complaints. In the extant literature, aspects of social support are associated with better mental health and quality of life among family caregivers to individuals with disabilities and/or chronic health conditions (Bemister et al., 2015; Klassen et al., 2007; Raina et al., 2004). For example, supportive conversations and larger social support networks have been linked with healthy behaviors and the seeking and acquisition of health information, and have been shown to influence tangible health support and coping assistance (Goldsmith \& Albrecht, 2011). These findings suggest that social support interventions may be a useful tool to promote psychological well-being in family caregivers during the transition to caregiving.

Consideration of the intrapersonal (e.g., preferences of the caregiver) and relational aspects of social support (e.g., quality of social support interactions) in intervention development may help to facilitate the effectiveness of resources provided. A common assumption in many clinical settings is that all social support is beneficial and that increased availability of social support is always a desirable outcome. This assumption fails to acknowledge the conceptual complexity of social support (Sarason \& Sarason, 2009) and limits the ability of individuals seeking to promote positive outcomes for family caregivers. For example, some studies have failed to find a positive relationship between social support and caregiver well-being (Smerglia et al., 2007), while others have found that negative social interactions in the context of "supportive" relationships contribute to worse emotional functioning and lower quality of life among caregivers (Williams \& Hankey, 2015). Additional aspects of social support, such as whether support was solicited by the caregiver or provided without prompting, may also play a role in the impact of social support on caregiver wellbeing (Feng \& Lee, 2010). Thus, social support interventions should ideally be tailored to address caregivers' unique support needs and preferences (Wittenberg-Lyles et al., 2014).

With respect to physical health status and needs, our findings are 
consistent with the extant literature highlighting poor health in informal caregivers as a significant concern. In large-scale epidemiological surveys, approximately 50\% of informal caregivers have been found to have at least one chronic health condition and over a third (33.0\%) report having a physical, mental, or emotional disability that limits their own functioning ("Caregiving for Family and Friends-A Public Health Issue,” 2019). Poorer health outcomes among informal caregivers are often attributed to the time-consuming nature of caregiving and lack of access to adequate respite care, which can result in limited opportunities for caregivers to address their own health care needs and personal well-being (Acton, 2002; Dionne-Odom et al., 2017; Oliveira et al., 2019). However, our findings indicate that many caregivers are already managing significant health problems at the onset of the caregiving role. Specifically, $45.5 \%$ of caregivers indicated that they have a chronic illness lasting 6 months or longer and nearly a fifth of these individuals reported that it interferes significantly with their daily functioning. Modifiable behaviors that may be contributing to poorer health in caregivers include low engagement in Positive Health Habits (e.g., regular physical activity, healthy dietary intake), which was reported by $43 \%$ of our sample, as well as Negative Health Habits (e.g., smoking), reported by almost a quarter of the sample. Together, these data highlight the need to provide health promotion interventions for informal caregivers to help them adopt healthy lifestyle habits at the time the caregiving role is assumed. Emerging research using dyadic approaches suggests that such interventions would not only confer benefits for caregivers' own health and well-being but could also lead to improved outcomes for the care recipient (Bidwell et al., 2017; Cipolletta et al., 2019; Meyers et al., 2020; Thomson et al., 2020).

The second aim was to examine whether family caregivers' needs vary according to the characteristics of the informal caregiver or care recipient. Identification of factors that influence caregivers' functioning is critical to identify vulnerable individuals and to develop effective interventions that promote caregivers' health and emotional wellbeing. Although many would benefit from intervention, our findings highlight two groups that may be at greatest need. First, a significant subgroup of caregivers (15\%-20\%) were experiencing problems in both physical and mental health. A family caregiver's own physical health has been identified as an influential factor in the decision 
to place a relative in a long-term care facility (Buhr et al., 2006). Individuals who are experiencing comorbid mental and physical health challenges may have a significantly decreased capacity to provide adequate care for their family member, resulting in poorer health outcomes for the care recipient, increased need for out-of-home care placement, and higher health care costs. There is evidence that psychosocial interventions provided to family caregivers can delay nursing home placement of individuals with dementia (Andrén \& Elmståhl, 2008; Gaugler et al., 2013). Development and implementation of interventions that offer the potential to improve both the physical and mental health of caregivers are needed.

Second, our findings also indicated that younger informal caregivers are faring worse than older caregivers in the medical rehabilitation hospital setting. This is a notable finding because it is often assumed that older adults are the most vulnerable population because the stress and demands associated with caregiving taxes their physical abilities and compromises their more vulnerable immune response systems, which in turn exacerbates existing chronic health conditions (Navaie-Waliser et al., 2002). However, more recent studies report similar levels of caregiver burden and quality of life across individuals from different generations (Kim et al., 2018). Moreover, younger caregivers face additional challenges that their older counterparts are less likely to encounter, such as unemployment or underemployment during caregiving, the responsibility of simultaneously providing both adult and child care, and having different family relationships with the care recipient (i.e., providing care for a child or parent vs. a spouse). In addition, attending to informal caregivers' race may be informative in understanding their well-being needs (Willert \& Minnotte, in press). Our results suggest that caregivers identifying as White/Caucasian were more likely to need tangible social supports whereas those identifying as racial/ethnic minorities indicated a higher need for professional help. The additional challenges found by age and race are associated with a constellation of well-established risk factors for poor health in informal caregivers, including being female, having lower socioeconomic status, residing with the care recipient, experiencing depression, financial stress and social isolation/ lack of social support, a higher number of hours engaged in caregiving tasks, and having a lack of choice in being a caregiver (Adelman et al., 2014; Bradshaw et al., 2019; Pilapil et al., 2017; Raina et al., 2004). 
The third aim was to examine caregivers' perspectives on the importance of self-care and their experiences and interest in mindfulness meditation. Using a readiness ruler approach, we found that the majority of caregivers surveyed reported that it was both very important for them to improve their physical and mental health and that they felt very confident they could do so. Research testing the clinical utility of the readiness ruler has shown that this assessment of individuals' motivation and readiness to change is predictive of actual behavior change in interventions (Hesse, 2006). Thus, our results indicating high readiness to change among informal caregivers in the rehabilitation setting suggests the onset of caregiving role would be an opportune moment for health and wellness interventions. This finding is consistent with an emerging literature documenting an interest in health promotion screening and interventions among family caregivers to people with chronic health conditions (Nightingale et al., 2019; Shaffer et al., 2019).

One type of intervention that may be beneficial for promoting health and wellness among informal caregivers is mindfulness meditation. In a recent review of 12 studies involving mindfulness and acceptance-based interventions with informal caregivers to people with dementia, improvements were observed in caregivers' depressive symptoms, psychological flexibility, and self-compassion in the face of stress (Collins \& Kishita, 2019). In another recent pilot study of cancer patients and their informal caregivers, participating in a mindfulness meditation intervention that included the mobile app Headspace was found feasible, well accepted, and associated with statistically significant reductions in distress, depression, and fatigue, and with increases in perceptions of general health (Kubo et al., 2019). Public and professional awareness of mindfulness has increased significantly in recent years, and mindfulness-based interventions for informal caregivers are growing with promising evidence in reducing informal caregivers' anxiety and depression (Hearn et al., 2019). In our sample, over half of participants reported that they had heard of mindfulness meditation and a third had engaged in the practice of meditation. Overall, receptivity to a mindfulness meditation-based intervention was high, with almost three-quarters of caregivers expressing an interest in learning more about this approach to health promotion. Thus, we conclude that mindfulness meditation may be an effective strategy to support the health, well-being, and resilience of informal caregivers within the physical rehabilitation context. 


\section{Study Limitations}

Several study limitations should be noted. Our small sample was not racially or ethnically diverse and was comprised mostly of female caregivers. This homogeneity limits the generalizability of our findings to other groups. In addition, we were not able to access any additional information from the medical record to provide insight into the clinical severity of the family members' conditions or aspects of their treatment, including length of stay. The physical rehabilitation setting where the research was conducted provides services for inpatients and outpatients from across the United States who are recovering from serious injuries and illnesses. Thus, generalizability to family caregivers of patients with less complex or severe functional disabilities is unknown. Study outcomes were assessed via caregiver self-report, which is subject to social desirability bias and recall bias. Similarly, this study relied on convenience sampling to recruit participants, and individuals who self-selected to participate in the research may be different than individuals who opted not to participate (e.g., may have worse well-being). Our assessment of caregiver functioning, while broad in scope, did not provide insight into other aspects of caregiver functioning that effect physical and emotional health. Specifically, strengths-based approaches informed by positive psychology highlight the importance of considering individuals' strengths and resilience-promoting factors that may be leveraged to facilitate health and psychological well-being, such as benefit finding and optimism (Bertisch et al., 2014; Brand et al., 2016; Donaldson et al., 2014; Fredrickson, 2000; Lianov et al., 2019; Park et al., 2016). Finally, a potential study limitation is it cannot be assumed that responses to the MHP-H items are due to informal caregiving or the circumstances that led to assumption of this role.

\section{Conclusions and Implications}

The challenges facing caregivers in both psychosocial and physical health domains in our sample of caregivers in a medical rehabilitation hospital highlight the importance of integrating assessment of the informal caregiver into health care delivery settings. There is need to 
develop and evaluate targeted interventions to improve caregiver wellbeing following the onset of the caregiving role, as a large number of caregivers are already facing threats to well-being. This study has important implications for systems and ecologically minded rehabilitation counselors whose scope of practice involves working with the family members who support individuals with disabilities as well as working directly with children and adults with disabilities. Research highlights the prominent role of family and caregiver social support in promoting resilience and positive outcomes for individuals with disabilities (Bhattarai et al., 2020). Caregivers' capacity to provide social support (and perform critical caregiving tasks) is reduced when they are experiencing challenges to their own health and psychological well-being. Awareness of the specific challenges facing caregivers to individuals with disabilities at the onset of the caregiving role may help rehabilitation counselors to design rehabilitation interventions that address these challenges early in treatment, leading to an improved capacity for social support and in turn desirable outcomes for individuals with disabilities.

Mindfulness meditation-based interventions appear to be a familiar and acceptable approach that may help to reduce the experience of stress and caregiver burden, placing informal caregivers on a positive trajectory for long-term health and well-being (Bolier et al., 2013). With their training in assessment, human behavior, and intervention, rehabilitation counselors are well positioned to incorporate this clinical approach into their practice. A key challenge in designing and delivering this type of intervention to family caregivers in the medical rehabilitation settings is systematically and accurately identifying those in need of services, and ensuring that the intervention is low burden to accommodate caregivers' busy schedules but sufficiently powerful to confer benefits.

$$
\ddagger \neq \ddagger \ddagger
$$

Conflicting Interests The authors declared no potential conflicts of interest with respect to the research, authorship, and publication of this article.

Funding The authors received no financial support for the research, authorship, and publication of this article. 


\section{References}

Acton, G. J. (2002). Health-promoting self-care in family caregivers. Western Journal of Nursing Research, 24(1), 73-86. https://doi. org/10.1177/01939450222045716

Adelman, R. D., Tmanova, L. L., Delgado, D., Dion, S., \& Lachs, M. S. (2014). Caregiver burden: A clinical review. Journal of the American Medical Association, 311(10), 1052-106o. https://doi.org/10.1001/jama.2014.304

Allen, A. P., Curran, E. A., Duggan, Á., Cryan, J. F., Chorcoráin, A. N., Dinan, T. G., Molloy, D. W., Kearney, P. M., \& Clarke, G. (2017). A systematic review of the psychobiological burden of informal caregiving for patients with dementia: Focus on cognitive and biological markers of chronic stress. Neuroscience and Biobehavioral Reviews, 73, 123-164. https://doi.org/10.1016/j. neubiorev.2016.12.006

Altman, B. M., \& Blackwell, D. L. (2016). Disability in U.S. households, 2000-2010: Findings from the national health interview survey. Family Relations, 63(1), 20-38. https://doi.org/10.1111/fare.12044

Andrén, S., \& Elmståhl, S. (2008). Effective psychosocial intervention for family caregivers lengthens time elapsed before nursing home placement of individuals with dementia: A fiveyear follow-up study. International Psychogeriatrics, 20(6), 1177-1192. https://doi.org/10.1017/ $\underline{S 1041610208007503}$

Bemister, T. B., Brooks, B. L., Dyck, R. H., \& Kirton, A. (2015). Predictors of caregiver depression and family functioning after perinatal stroke. BMC Pediatrics, 15, Article 75. https://doi.org/10.1186/s12887-015-0397-5

Bertisch, H., Rath, J., Long, C., Ashman, T., \& Rashid, T. (2014). Positive psychology in rehabilitation medicine: A brief report. Neurorehabilitation, 34(3), 573-585.

Bhattarai, M., Smedema, S. M., \& Maneewat, K. (2020). An integrative review of factors associated with resilience post-spinal cord injury. Rehabilitation Counseling Bulletin. Advance online publication. https://doi. org/10.1177/0034355220938429

Bidwell, J. T., Lyons, K. S., \& Lee, C. S. (2017). Caregiver wellbeing and patient outcomes in heart failure: A meta-analysis. The Journal of Cardiovascular Nursing, 32(4), 372-382. https://doi.org/10.1097/JCN.0000000000000350

Bishop, S. R., Lau, M., Shapiro, S., Carlson, L., Anderson, N. D., Carmody, J., Segal, Z. V., Abbey, S., Speca, M., Velting, D., \& Devins, G. (2004). Mindfulness: A proposed operational definition. Clinical Psychology: Science and Practice, 11(3), 230-241. https://doi.org/10.1093/clipsy.bpho77

Bolier, L., Haverman, M., Westerhof, G. J., Riper, H., Smit, F., \& Bohlmeijer, E. (2013). Positive psychology interventions: A meta-analysis of randomized controlled studies. BMC Public Health, 13, Article 119. https://doi.

org/10.1186/1471-2458-13-119 
Bouldin, E. D., Shaull, L., Andresen, E. M., Edwards, V. J., \& McGuire, L. C. (2018). Financial and health barriers and caregiving-related difficulties among rural and urban caregivers. The Journal of Rural Health, 34(3), 263-274. https://doi. org/10.1111/jrh.12273

Bradshaw, S., Bem, D., Shaw, K., Taylor, B., Chiswell, C., Salama, M., Bassett, E., Kaur, G., \& Cummins, C. (2019). Improving health, wellbeing and parenting skills in parents of children with special health care needs and medical complexity-A scoping review. BMC Pediatrics, 19(1), Article 301. https://doi. org/10.1186/s12887-019-1648-7

Brand, C., Barry, L., \& Gallagher, S. (2016). Social support mediates the association between benefit finding and quality of life in caregivers. Journal of Health Psychology, 21(6), 1126-1136. https://doi. org/10.1177/1359105314547244

Buhr, G. T., Kuchibhatla, M., \& Clipp, E. C. (2006). Caregivers' reasons for nursing home placement: Clues for improving discussions with families prior to the transition. The Gerontologist, 46(1), 52-61. https://doi.org/10.1093/ geront/46.1.52

Buttorff, C., Ruder, T., \& Bauman, M. (2017). Multiple chronic conditions in the United States [Product page]. https://www.rand.org/pubs/tools/TL221.html

Caregiving for family friends-A public health issue. (2019, July 31). https://www. cdc.gov/aging/caregiving/caregiver-brief.html

Choi, J., Son, Y.-J., \& Tate, J. A. (2019). Exploring positive aspects of caregiving in family caregivers of adult ICU survivors from ICU to four months post-ICU discharge. Heart \& Lung: The Journal of Critical Care, 48, 553-559. https://doi. org/10.1016/j.hrtlng.2019.09.001

Cipolletta, S., Entilli, L., Nucci, M., Feltrin, A., Germani, G., Cillo, U., \& Volpe, B. (2019). Psychosocial support in liver transplantation: A dyadic study with patients and their family caregivers. Frontiers in Psychology, 10, Article 2304. https://doi.org/10.3389/fpsyg.2019.02304

Collins, R. N., \& Kishita, N. (2019). The effectiveness of mindfulness- and acceptance-based interventions for informal caregivers of people with dementia: A meta-analysis. The Gerontologist, 59(4), e363-e379. https://doi. org/10.1093/geront/gnyo24

Dharmawardene, M., Givens, J., Wachholtz, A., Makowski, S., \& Tjia, J. (2016). A systematic review and meta-analysis of meditative interventions for informal caregivers and health professionals. BMJ Supportive \& Palliative Care, 6(2), 16o-169. https://doi.org/10.1136/bmjspcare-2014-000819

Dionne-Odom, J. N., Demark-Wahnefried, W., Taylor, R. A., Rocque, G. B., Azuero, A., Acemgil, A., Martin, M. Y., Astin, M., Ejem, D., Kvale, E., Heaton, K., Pisu, M., Partridge, E. E., \& Bakitas, M. A. (2017). The self-care practices of family caregivers of persons with poor prognosis cancer: Differences by varying levels of caregiver well-being and preparedness. Supportive Care in Cancer, 25(8), 2437-2444. https://doi.org/10.1007/s00520-017-3650-7 
Donaldson, S. I., Dollwet, M., \& Rao, M. A. (2014). Happiness, excellence, and optimal human functioning revisited: Examining the peer-reviewed literature linked to positive psychology. The Journal of Positive Psychology, 10, 185-195.

Edwards, V. J. (2020). Characteristics and health status of informal unpaid caregivers-44 states, District of Columbia, and Puerto Rico, 2015-2017. MMWR. Morbidity and Mortality Weekly Report, 69, 183-188. https://doi. org/10.15585/mmwr.mm6907a2

Feng, B., \& Lee, K. J. (2010). The influence of thinking styles on responses to supportive messages. Communication Studies, 61(2), 224-238. https://doi. org/10.1080/10510971003604000

Frambes, D., Given, B., Lehto, R., Sikorskii, A., \& Wyatt, G. (2017). Informal caregivers of cancer patients: Review of interventions, care activities, and outcomes. Western Journal of Nursing Research, 40, 1069-1097. https://doi. org/10.1177/0193945917699364

Fredrickson, B. L. (2000). Cultivating positive emotions to optimize health and well-being. Prevention \& Treatment, 3(1), Article 1 a.

Gaugler, J. E., Reese, M., \& Mittelman, M. S. (2013). Effects of the NYU caregiver intervention-adult child on residential care placement. The Gerontologist, 53(6), 985-997. https://doi.org/10.1093/geront/gns193

Geng, H.-M., Chuang, D.-M., Yang, F., Yang, Y., Liu, W.-M., Liu, L.-H., \& Tian, H.M. (2018). Prevalence and determinants of depression in caregivers of cancer patients: A systematic review and meta-analysis. Medicine, 97(39), Article e11863. https://doi.org/10.1097/MD.0000000000011863.

Goldsmith, D. J., \& Albrecht, T. L. (2011, August 24). Social support, social networks, and health. In T. L. Thompson, R. Parrott, \& J. F. Nussbaum (Eds.), The Routledge handbook of health communication (pp. 335-348). Routledge. https://doi.org/10.4324/9780203846063.ch21

Hearn, J. H., Cotter, I., \& Finlay, K. A. (2019). Efficacy of internet-delivered mindfulness for improving depression in caregivers of people with spinal cord injuries and chronic neuropathic pain: A randomized controlled feasibility trial. Archives of Physical Medicine and Rehabilitation, 10o(1), 17-25. https://doi. org/10.1016/j.apmr.2018.08.182

Hesse, M. (2006). The readiness ruler as a measure of readiness to change polydrug use in drug abusers. Harm Reduction Journal, 3, Article 3. https://doi. org/10.1186/1477-7517-3-3

Jolliffe, L., Lannin, N. A., Cadilhac, D. A., \& Hoffmann, T. (2018). Systematic review of clinical practice guidelines to identify recommendations for rehabilitation after stroke and other acquired brain injuries. BMJ Open, 8(2), Article e018791. https://doi.org/10.1136/bmjopen-2017-018791

Kabat-Zinn, J. (1994). Wherever you go, there you are. https://www.biblio.com/ wherever-you-go-there-you-by-kabat-zinnjon/work/39959

Karoly, P., Ruehlman, L. S., \& Lanyon, R. I. (2005). The assessment of adult health care orientations: Development and preliminary validation of the Multidimensional Health Profile-Health Functioning Index (MHP-H) in a 
national sample. Journal of Clinical Psychology in Medical Settings, 12(1), 7991. https://doi.org/10.1007/s10880-005-0915-y

Kim, H., Lee, S., Cheon, J., Hong, S., \& Chang, M. (2018). A comparative study to identify factors of caregiver burden between baby boomers and post baby boomers: A secondary analysis of a US online caregiver survey. BMC Public Health, 18(1), Article 579. https://doi.org/10.1186/s12889-018-5488-4

Klassen, A., Raina, P., Reineking, S., Dix, D., Pritchard, S., \& O’Donnell, M. (2007). Developing a literature base to understand the caregiving experience of parents of children with cancer: A systematic review of factors related to parental health and well-being. Supportive Care in Cancer, 15(7), 807-818. https://doi. org/10.1007/s00520-007-0243-X

Kubo, A., Kurtovich, E., McGinnis, M., Aghaee, S., Altschuler, A., Quesenberry, C., Kolevska, T., \& Avins, A. L. (2019). A randomized controlled trial of mHealth mindfulness intervention for cancer patients and informal cancer caregivers: A feasibility study within an integrated health care delivery system. Integrative Cancer Therapies, 18, Article 1534735419850634. https://doi. org/10.1177/1534735419850634

Lianov, L. S., Fredrickson, B. L., Barron, C., Krishnaswami, J., \& Wallace, A. (2019). Positive psychology in lifestyle medicine and health care: Strategies for implementation. American Journal of Lifestyle Medicine, 13(5), 480-486. https://doi.org/10.1177/1559827619838992

Liu, Y., Dokos, M., Fauth, E. B., Lee, Y. G., \& Zarit, S. H. (2019). Financial strain, employment, and role captivity and overload over time among dementia family caregivers. The Gerontologist, 59(5), e512-e520. https://doi.org/10.1093/ geront/gnzogg

Meyers, E., Lin, A., Lester, E., Shaffer, K., Rosand, J., \& Vranceanu, A.-M. (2020). Baseline resilience and depression symptoms predict trajectory of depression in dyads of patients and their informal caregivers following discharge from the Neuro-ICU. General Hospital Psychiatry, 62, 87-92. https://doi.org/10.1016/j. genhosppsych.2019.12.003

Miller, W. R., \& Rollnick, S. (2002). Motivational interviewing: Preparing people for change (2nd ed.). The Guilford Press. Nas, L. Y., Yazmalar, L., Şah, V., Aydın, A., \& Öneş, K. (2015). Rehabilitation of spinal cord injuries. World Journal of Orthopedics, 6(1), 8-16. https://doi.org/10.5312/wjo.v6.i1.8

Navaie-Waliser, M., Feldman, P. H., Gould, D. A., Levine, C., Kuerbis, A. N., \& Donelan, K. (2002). When the caregiver needs care: The plight of vulnerable caregivers. American Journal of Public Health, 92(3), 409-413.

Nightingale, C. L., Steffen, L. E., Tooze, J. A., Petty, W., Danhauer, S. C., Badr, H., \& Weaver, K. E. (2019). Lung cancer patient and caregiver health vulnerabilities and interest in health promotion interventions: An exploratory study. Global Advances in Health and Medicine, 8, 1-11. https://doi. org $/ 10.1177 / 2164956119865160$

Ochoa, C. Y., Buchanan Lunsford, N., \& Lee Smith, J. (2019). Impact of informal cancer caregiving across the cancer experience: A systematic literature review 
of quality of life. Palliative \& Supportive Care, 18, 220-240. https://doi. org/10.1017/S1478951519000622

Oliveira, D., Sousa, L., \& Orrell, M. (2019). Improving healthpromoting self-care in family carers of people with dementia: A review of interventions. Clinical Interventions in Aging, 14, 515-523. https://doi.org/10.2147/CIA.S190610

Or, R., \& Kartal, A. (2019). Influence of caregiver burden on well-being of family member caregivers of older adults. Psychogeriatrics: The Official Journal of the Japanese Psychogeriatric Society, 19(5), 482-490. https://doi.org/10.1111/ psyg.12421

Park, N., Peterson, C., Szvarca, D., Vander Molen, R. J., Kim, E. S., \& Collon, K. (2016). Positive Psychology and Physical Health: Research and Applications. American Journal of Lifestyle Medicine, 10(3), 200-206. https://doi. org/10.1177/1559827614550277

Pilapil, M., Coletti, D. J., Rabey, C., \& DeLaet, D. (2017). Caring for the Caregiver: Supporting Families of Youth With Special Health Care Needs. Current Problems in Pediatric and Adolescent Health Care, 47(8), 190-199. https://doi. org/10.1016/j.cppeds.2017.07.003

Raina, P., O’Donnell, M., Schwellnus, H., Rosenbaum, P., King, G., Brehaut, J., Russell, D., Swinton, M., King, S., Wong, M., Walter, S. D., \& Wood, E. (2004). Caregiving process and caregiver burden: Conceptual models to guide research and practice. BMC Pediatrics, 4 , Article 1. https://doi. org/10.1186/1471-2431-4-1

Ruehlman, L. S., Lanyon, R. I., \& Karoly, P. (1999). Development and validation of the Multidimensional Health Profile, part I: Psychosocial functioning. Psychological Assessment, 11(2), 166-176.

Sarason, I. G., \& Sarason, B. R. (2009). Social support: Mapping the construct. Journal of Social and Personal Relationships, 26(1), 113-120. https://doi. org/10.1177/0265407509105526

Schulz, R., \& Sherwood, P. R. (2008). Physical and mental health effects of family caregiving. The American Journal of Nursing, 108(Suppl. 9), 23-27. https://doi. org/10.1097/01.NAJ.0000336406.45248.4C

Shaffer, K. M., Benvengo, S., Zaleta, A. K., Levine, M., Bellantoni, C., Dannaoui, A., Buzaglo, J. S., \& Applebaum, A. J. (2019). Feasibility and acceptability of distress screening for family caregivers at a cancer surgery center. Oncology Nursing Forum, 46(2), 159-169. https://doi.org/10.1188/19.ONF.159-169

Smerglia, V. L., Miller, N. B., Sotnak, D. L., \& Geiss, C. A. (2007). Social support and adjustment to caring for elder family members: A multistudy analysis. Aging \& Mental Health, 11(2), 205-217. https://doi. org/10.1080/13607860600844515

Stevens, A. C., Carroll, D. D., Courtney-Long, E. A., Zhang, Q. C., Sloan, M. L., Griffin-Blake, S., \& Peacock, G. (2016). Adults with one or more functional disabilities-United States, 2011-2014. MMWR. Morbidity and Mortality Weekly Report, 65(38), 1021-1025. https://doi.org/10.15585/mmwr.mm6538a1 
Talley, R. C., \& Crews, J. E. (2007). Framing the public health of caregiving. American Journal of Public Health, 97(2), 224-228. https://doi.org/10.2105/ AJPH.2004.059337

Tang, W., Friedman, D. B., Kannaley, K., Davis, R. E., Wilcox, S., Levkoff, S. E., Hunter, R. H., Gibson, A., Logsdon, R. G., Irmiter, C., \& Belza, B. (2019). Experiences of caregivers by care recipient's health condition: A study of caregivers for Alzheimer's disease and related dementias versus other chronic conditions. Geriatric Nursing (New York, N.Y.), 4O(2), 181-184. https://doi. org/10.1016/j.gerinurse.2018.09.012

Thomson, P., Howie, K., Leslie, S. J., Angus, N. J., Andreis, F., Thomson, R., Mohan, A. R. M., Mondoa, C., \& Chung, M. L. (2020). Evaluating emotional distress and health-related quality of life in patients with heart failure and their family caregivers: Testing dyadic dynamics using the Actor-Partner Interdependence Model. PLOS ONE, 15(1), Article eo227129. https://doi.org/10.1371/journal. pone.0227129

Willert, B., \& Minnotte, K. L. (in press). Informal caregiving and strains: Exploring the impacts of gender, race, and income. Applied Research in Quality of Life. https://doi.org/10.1007/s11482-019-09786-1

Williams, N. A., \& Hankey, M. (2015). Support and negativity in interpersonal relationships impact caregivers' quality of life in pediatric food allergy. Quality of Life Research: An International Journal of Quality of Life Aspects of Treatment, Care and Rehabilitation, 24(6), 1369-1378. https://doi.org/10.1007/ s11136-014-0862-X

Winstein, C. J., Stein, J., Arena, R., Bates, B., Cherney, L. R., Cramer, S. C., Deruyter, F., Eng, J. J., Fisher, B., Harvey, R. L., Lang, C. E., MacKay-Lyons, M., Ottenbacher, K. J., Pugh, S., Reeves, M. J., Richards, L. G., Stiers, W., Zorowitz, R. D., \& American Heart Association Stroke Council, Council on Cardiovascular Stroke Nursing, Council on Clinical Cardiology, and Council on Quality of Care Outcomes Research. (2016). Guidelines for adult stroke rehabilitation and recovery: A guideline for healthcare professionals from the American Heart Association/American Stroke Association. Stroke, 47(6), e98-e169. https://doi. org/10.1161/STR.0000000000000098

Wittenberg-Lyles, E., Washington, K., Demiris, G., Parker Oliver, D., \& Shaunfield, S. (2014). Understanding social support burden among family caregivers.

Health Communication, 29(9), 901-910. https://doi.org/10.1080/10410236.201 3.815111

Yu, D. S. F., Cheng, S.-T., \& Wang, J. (2018). Unravelling positive aspects of caregiving in dementia: An integrative review of research literature. International Journal of Nursing Studies, 79, 1-26. https://doi.org/10.1016/j. ijnurstu.2017.10.008

Zavagli, V., Miglietta, E., Varani, S., Pannuti, R., Brighetti, G., \& Pannuti, F. (2016). Associations between caregiving worries and psychophysical well-being. An investigation on homecared cancer patients family caregivers. Supportive Care in Cancer: Official Journal of the Multinational Association of Supportive Care in Cancer, 24(2), 857-863. https://doi.org/10.1007/s00520-015-2854-y 